التوجه التنافسي وعلاقته بدافعية الاتجاز الرياضى والسلوك التنافسي لاى ناشئ

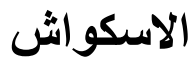

\title{
ايه مشهور
}

مدرس بقسم علم النفس الرياضي

كلية التربية الرياضية جامعة طنطا لياضي

مقدمة البحث

أن التطور الكبير في مجال الرياضة لم يكون من فراغ ولكن نتيجة الاهتمام الكبير بالبحوث

العلمية التي اضافت الى المعرفة الثيء الكثير والتي بفضلها نم تحقيق الكثير من الانجازات الرياضية في جميع الالعاب التي تحتاج الى امتلاك اللاعبين الكثير من المواصفات منها البدنية و الجسمية و الوظيفية و النفسية.

ويعد علم النفس من العلوم التي ساهتت في وصول الرياضي الى تحقيق اعلى المستويات اذ يهدف الى توجيههم بهدف الارتقاء بما يمتلكونه من قدرات على مو اجهة الصعوبات التي تعترضهم

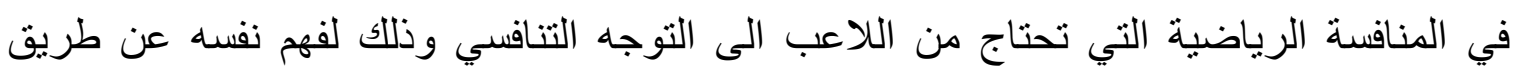

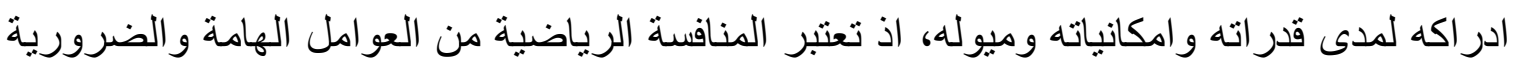

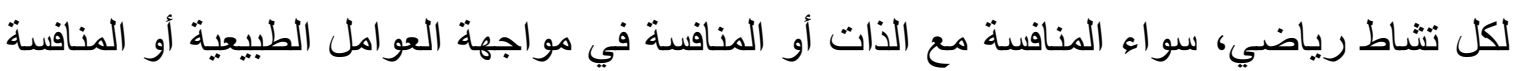

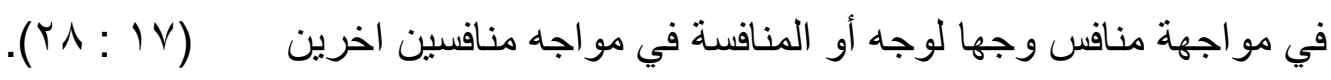
ان عملية اعداد اللاعبين اعدادا متكاملا يجب ان تتضمن جميع النواحي ومنها الناحية

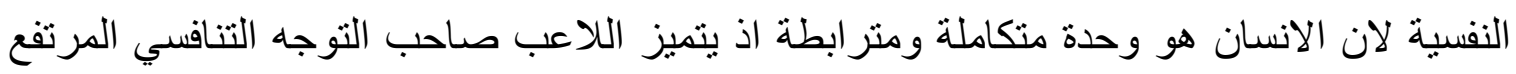
بتركيزه على النتائج المتوقعة وارتباطها بالنجاح وان معرفة اللاعب لإمكانياته يساعده على فهم

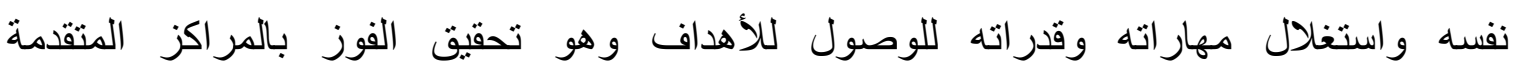
$(1 \wedge 1: 10)$

حيث يلعب عامل التوجه الرياضي نقطة فعالة ومثيرة نحو هدف مرسوم على حقيقة علمية

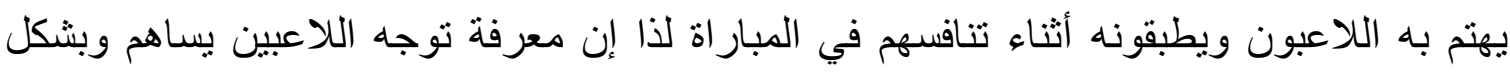

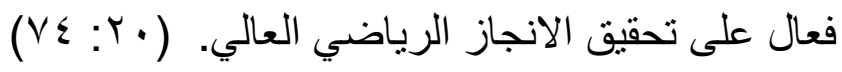
ويرتبط التوجه باشتراك اللاعب في المنافسة واضعا نصب عينه محاولة نظوير مستواه وتحسينه عن الأداء السابق له وبذل أقصى جهذ ممكن في الأداء وإظهار أكبر قدر مدكن من قدر اته 
و لا يرتبط ذلك بمقارنة مستو اه بمسنوى الآخرين ولكن بمحاولة تطوير وتحسين مستواه في ضوء مستوياته السابقة وبالتالي شعوره بالنجاح في حالة تحقيق ذلك وشعوره بالفشل عند عدم تحقيق

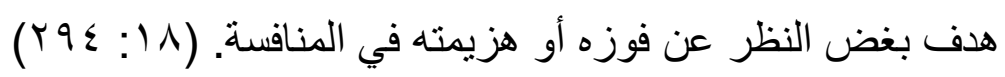

ويكون ذلك بتوجه الفرد الرياضي نحو السيطرة على المهةة، أو التحسن الشخصي، نتيجة لإدر اكه لقرراته، و هدف هذه القدرة إذ يكتشف الرياضي هنا قدر اته وكيفية توجه هذه القدرة نحو انجاز المهام التي يتكلف بها أو يسعى إليها وهذا يعكس بالنسبة للرياضي كفاءة عالية ونجاح

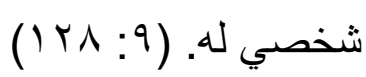

وذلك بمحاولـة توجيـه دافعية الانجاز لـدى الرياضي أمـا توجه نحو النتيجة وهـو الرغبة في الفوز أو الحصـول على مركز عال بالنسبة للمنافسين الآخرين أو توجه الأداء الذي يثنير إلى هدف الأداء الجيد بالنسبة لقدرة الفرد الرياضي نفسه. (r ب: (9 ( ))

وان دافعية الإنجاز الرياضي مـن السـمات النفسية المهمـة التي تأثر على مسـتوى الرياضـي أثنـاء المنافسات لكونهـا تعبـر عـن استعداد الرياضـي لبـل أقصى جهـ مـن أجلـ تحقيق الفوز مـن المنافسة أو المبار اة. ودافعية الإنجاز الرياضي هي تكوين متعدد الأبعاد ومـن هذه الأبعاد هدف الإنجاز الذي يكون في الاهتمام الأكبر للاعب لمواجهة متطلبات المنافسة وانها مـن أهم المحددات الأساسية

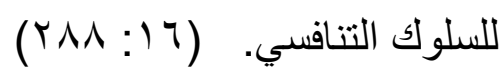
أن المستوى الأمثل للافعية يكون في موقف المنافسة الذي يتطلب مستوى ملائم من الاستثارة إذ إن لكل اعب مستوى ملائم من الاسـتثارة حتى يحقق أفضل أداء فى موقف المنافسة.

وللافعية وظائف متعددة وتكون هذه الوظائف باتجاهين: الاتجاه الأول: هـو إن الدافع لـه وظيفـة توجيهيـة هـى تشـير إلى اختيـار اللاعب للنشـاط

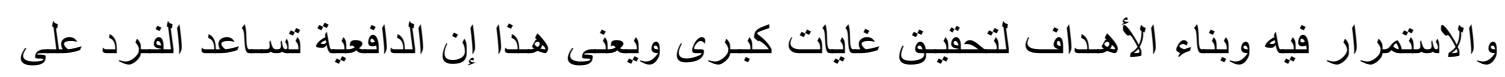
اختبـار الوسـائل لتحقيق الحاجات عن طريق وضعة على اتصال مع بعض المثيرات المهمة لأجل بقاءه. الاتجاه الثانى: إن للدافع وظيفة تنشيطية أي استمرار السلوك طالما بقي الرياضى مدفعا أو طالما

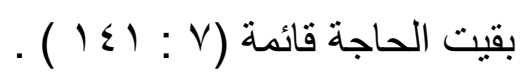


وتعـد حاجـة الرياضـى للثـعور بالاقتـار والانجـاز هـو السير وراء مقدرته الكامنة على الانجـاح لذلك يعمل الرياضى على إظهار حاجة قوية للإنجاز من خلال (إظهار مقدارا عاليا من المثابرة على تطور الأداء -إظهار خصائص نوعية من المهارات والأداء-إظهار قدرا مرتفعا من إنجاز الأداء في التدريب والمنافسة ـالتوجه نحو المهارة أكثر من التوجه نحو الذات ـتقدير المواقف و التعامل بو اقعية مع مو اقف الضغط و المخاطرة). (9 (1: وس ( )

ولتحقيق الهدف من قبل الرياضي يحتاج الى توجيه سلوكه نحو المنافسة الرياضية اذ ان السلوك التنافسي هو الاستجابات التي تصدر من اللاعب نتيجة احتكاكه بغيره من اللاعبين او نتيجة اتصاله بالبيئة الخارجية من حوله ويتضمن السلوك بهذا المعنى كل ما يصدر عن اللاعب من عمل هل حركي، او تفكير او سلوك لغوي او مشاعر او انفعالات او ادر اكات (r :Tr).

إن التغير المستمر فى مكـان وحالـة وظـروف المنافسة وموعد إجر اءها وكذلك تغير المتنافسـون وسـاتهم ودرجـة تحضير اتهم ومدى معـرفتهم لبعضـهم البعض وهذا يتطلب مـن الرياضى حـل سـريع للمهام الجديدة وتقييم الموقف واتخاذ القرار ات المناسبة التى تؤثر فى سلوك الرياضـى وان أسـباب السلوك تكمـن فى الدو افع وخبرات التعلم وتغير ات النضج. و السـلوك قصـدي وليس عشوائي فهنالك أغر اض يسـى السلوك أن يحققها فإثباع الحاجات

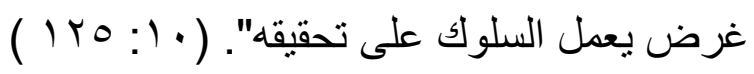
وسيظهر السلوك خـلال الهجـوم والدفاع في المحاولات الفرديـة التي يقوم بهـا اللاعب دون الاعتماد المباشر على زملائه فى الفريق بالرغم من إمكانية التعاون معهم (r: برم) فالمنافسة هى مرحلة عليا في تركيب النشـاط الرياضى فهى تسـمح للجميع بمشـاهدة جوانـب القوة و الضعف في النواحى البدنيـة والنفسية والمهاريـة وتعدـل على تنميـة وصـقل هـذه الصفات لدى الرياضى والتى تتعكس على السلوك التنافسى لديه من خلال استجابة لتفاعل حسافين في داخل الفرد الحسافز الأول صـاعداً للأعلى لمواصلة تحقيق قدرات اللاعب

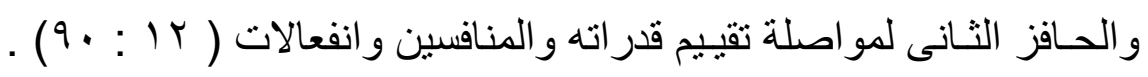
هنالك عوامل عديدة تؤثر على السلوك التنافسى للاعب خاصة فى المواقف التنافسية ومنها:

الفروق الفردية بين اللاعبين: سواء فى العمر، أو الجنس أو التقافة أو السمات

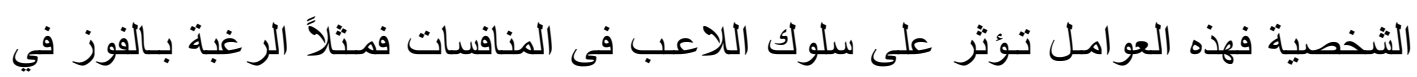


المنافسات تزداد مـع زيـادة العمر والمكافأة والثـهرة تكون مناسبة للذكور أكثر مـن

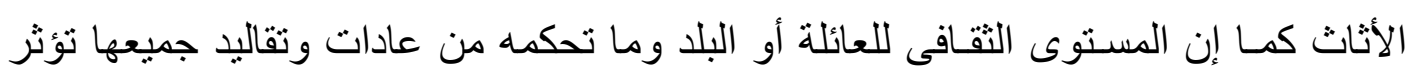

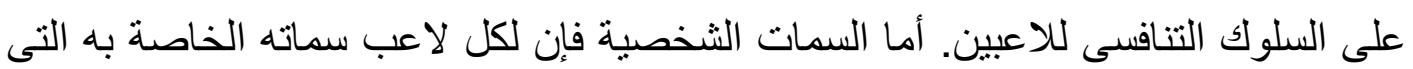
تميز سلوكهم.

مكونات موقف المنافسة: اذ إن المنافسة تجعل اللاعبين يتميزون بسلوكيات

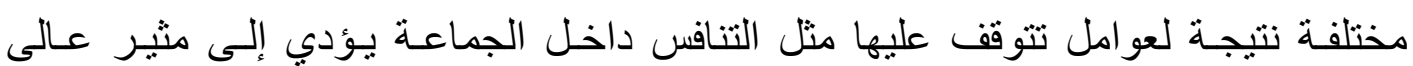

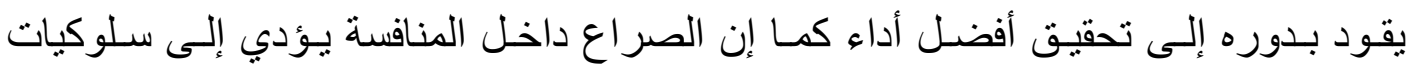

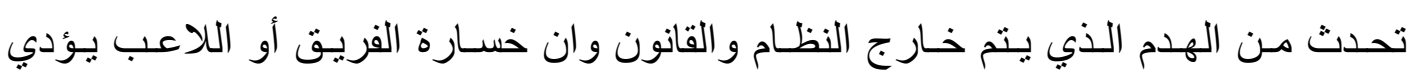

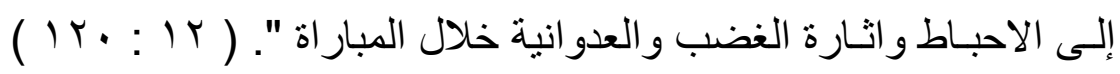
وتعددت الدراسات التي اهتمت بمتغيرات البحث كدراسة كل من فراس طالب حمادى و

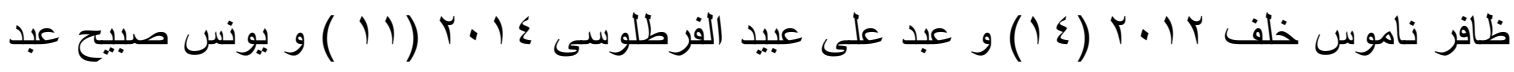

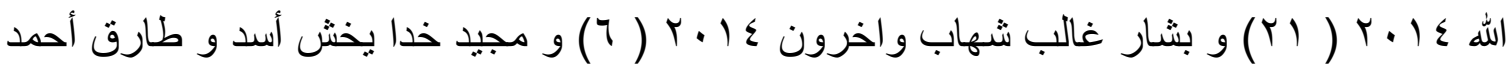

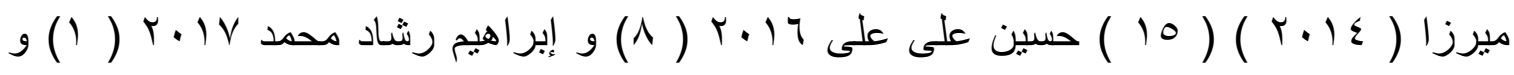

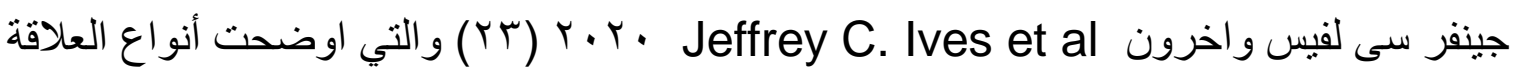

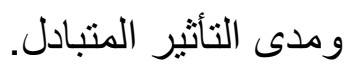

ان لعبة الأسكواش من الألعاب الفردية التي لها خصائص ومميزات تختلف عن بقية

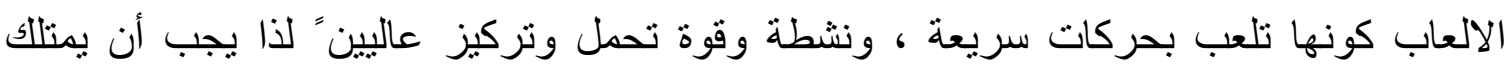
الاعب العديد من القدارت البدنية، والمهارية، والعقلية، والسمات النفسية والتي بمجلها يكون

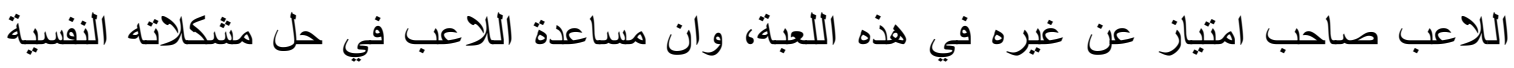
وتقديريه وتتجيعيه و الايمان بقدارته وخبارنه التي اكتسبها من خلال التمرين ، وتعزيز النجاح فيه

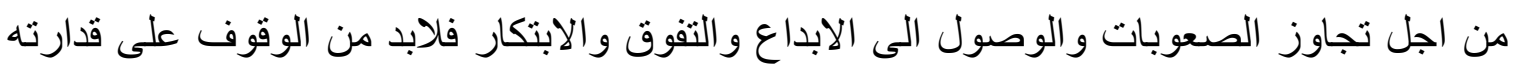

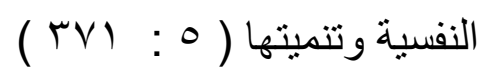

إن مهار ات الاسكواش مهارات معقدة وصعبة وذللك لكثرة أنواعها وتعدد استخداماتها في النقطة الواحدة، كما إن اغلب هذه المهارات تصنف ضمن المهارات المفتوحة والتي تكون بيئتها

$$
\text { غير متوقعة (IVT) }
$$

ولذلك ارتأت الباحثة من خلال متابعتها لمباريات الاسكواش المحلية وجود تذبذب في أداء

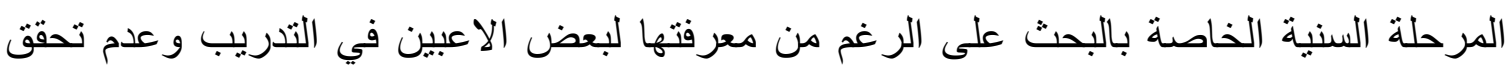


النتائج المرجوة منهم مما دفع الباحثة ة الوقوف على أسباب عدم استقرار أداء الاعبين في هذه المرحلة بأسلوب علمى للوقوف على أسبابها مما قد تساعد المدربين والاعبين في تحسين مستو اهم. هدف البحث: يهدف البحث الى التعرف على علاقة التوجه التنافسي بدافعية الانجاز الرياضى و السلوك التنافسي لدى لاعبى الاسكو اش

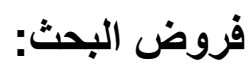

- توجد علاقة ارتباط ذات دالة معنوية بين التوجه التنافسى والدافعية الكلية لدى ناثئ الاسكو اش. - توجد علاقة ارتباط غير دالة معنوية بين التوجه التنافسى والسلوك التنافسى لدى ناثئ الاسكو اش. منهج البحث: استخدمت الباحثة المنهج الوصفى لملائمته طبيعة البحث عينة البحث: • ب لاعب في المرحلة السنية تحت 10 سنة مجالات البحث

المجال المكانى: في بطولة الجمهورية للناشئين بمجمع ملاعب نادى مدينتى الرياضى المجال الزمنى: في الفترة من الثناثاء 9 / / 9 1 ـ ب الى الاثثين 0 // ع / 9 ـ ـ م م

\begin{tabular}{|c|c|c|c|c|c|}
\hline الالتو اء & التقلطلح & الانحر اف & الوسط & متوسط & \\
\hline-.421 & -.623 & .94989 & 72.0000 & 71.8333 & التوجه التنافسي \\
\hline .179 & -.976 & 1.17884 & 32.0000 & 32.3000 & دافع انجاز النجاح \\
\hline-.787 & -.890 & 1.48904 & 34.0000 & 33.7000 & دافع تجنب الفشل \\
\hline-.976 & .715 & 1.37674 & 68.0000 & 67.3667 & الدافعية الكلية \\
\hline-.738 & -.185 & 1.44993 & 47.0000 & 46.9667 & السلوك التنافسى \\
\hline
\end{tabular}


يتضح من جدول ( ( ) تراوحت معاملات الالتو اء ما بين للارجة الكلية للسلوك التقاضي،

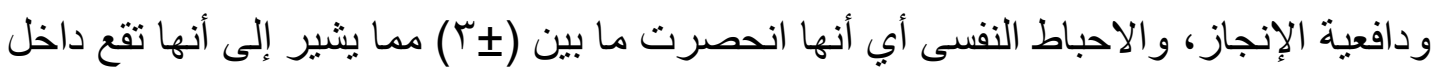
المنحنى الاعتدالي وبذلك تكون العينة موزعة توزيعا اعتداليا فى جميع متغير ات البحث.

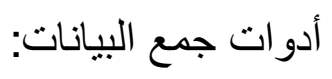

أو لا: مقياس التوجه التنافسي. إعداد محمد حسن علاوي (991 (م). ثانيا: مقياس دافعية الانجاز. إعدادا جون ولس وقام بتعريبه محمد حسن علاوى (991 ام) ثالثا: مقياس السلوك التنافسي. إعداد دورثي هاريس وقام بتعريبه محمد حسن علاوي (991 (م). أو لا: مقياس التوجه التنافسي: ملحق ( () وصف المقياس:

قائمــة التوجـهـ لتنافسي صممها محمد حسن عـلاوي لقياس التوجه لتنافسي للاعب الرياضى

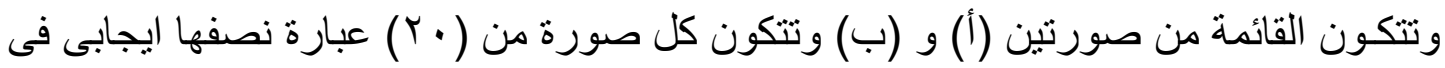

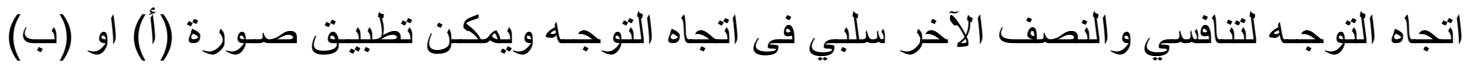

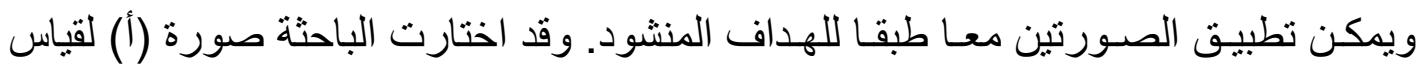
التوجه لتنافسي للاعب الاسكو اش.

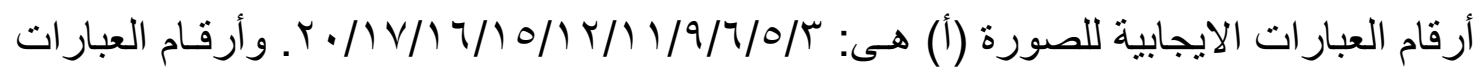

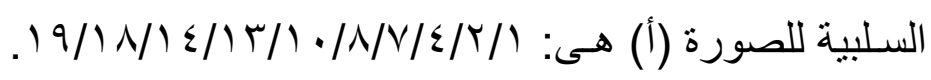
المعاملات العلمية لمقياس السلوك التنافسي في الدراسة الحالية:

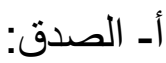
لحساب صدق المقياس استخدمت الباحثة صدق الاتساق الداخلي:

للتحقق من صدق المقياس قامت الباحثة بحساب صدق الاتساق الداخلي وذلك بتطبيقه على عينة قو امها (10 ) لاعب من لاعبي الاسكو اش من مجتمع البحث ومن خارج العينة الأساسية للبحث، ثم

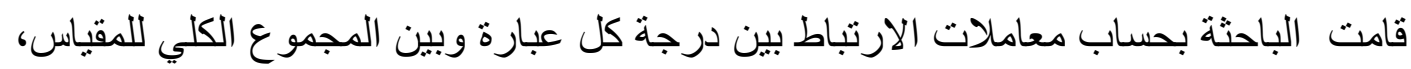
و الجدول (r) يوضح ذللك. 
جدول (r) ( )

معاملات الارتباط بين درجة كل عبارة من عبار ات مقياس التوجه التنافسى و المجموع الكلى

$$
\text { للمقياس ن= } 10
$$

\begin{tabular}{|c|c|c|c|}
\hline معاملات الارتباط & رقم العبارة & معاملات الارتباط & رقم العبارة \\
\hline $.894^{* *}$ & 11 & $.551^{*}$ & 1 \\
\hline $.638^{*}$ & IY & $.683 * *$ & $\bar{r}$ \\
\hline $.762 * *$ & $1 T$ & $.758 * *$ & $r$ \\
\hline $.743 * *$ & $1 \leqslant$ & $.712 * *$ & $\varepsilon$ \\
\hline $.671 * *$ & 10 & $.782 * *$ & $\circ$ \\
\hline $.784 * *$ & 17 & $.753 * *$ & 7 \\
\hline $.635^{*}$ & IV & $.741 * *$ & $\bar{v}$ \\
\hline $.823 * *$ & 11 & $.645 * *$ & $\Lambda$ \\
\hline $.740 * *$ & 19 & $.682 * *$ & 9 \\
\hline $.624^{*}$ & $r \cdot$ & $.556^{*}$ & 1. \\
\hline
\end{tabular}

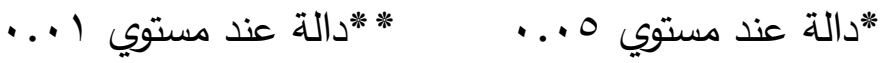

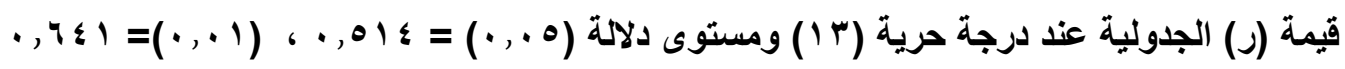

يتضح من جدول (Y) ان معاملات الارتباط بين درجة كل عبارة من عبار ات المقياس

و المجموع الكلي للمقياس تراوحت ما بين (551.: 894. ) وهى معاملات ارتباط دالة احصائياً مما

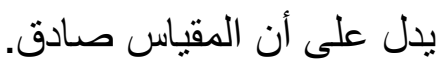

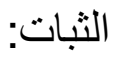

لحساب ثبات المقياس استخدمت الباحثة معامل الفا كرونباخ: للتأكد من ثبات المقياس قامت الباحثة باستخدام معامل ألفا لكرونباخ وذلك بتطبيقه على على عينة قو امها (0 1 ) لاعب من لاعبي الاسكو اش من مجتمع البحث ومن خارج العينة الأساسية للبحث و الجدول (r) يوضح ذلك.

جدول (ץ) معامل الفا ( كرونباخ ) لبيان معامل الثبات لمقياس التوجه التنافسى ن= 15

\begin{tabular}{|c|c|c|}
\hline معامل الفا كرونباخ & المتغير & b \\
\hline .854 & مقياس السلوك التنافسى & \\
\hline
\end{tabular}

يتضح من الجدول (r) ان قيمة معامل الفا كرنباخ لثبات مقياس التوجه التنافسى ( 854.) وهو معامل دال احصائيا مما يدل على ثبات المقياس 
ثانيا: مقياس السلوك التنافسي: ملحق (Y) وصف المقياس:

قامت دورثي هاريس (ع 9 (م) بنقتين مقياس السلوك التنافس وقام (محمد علاوي) بتعريبه

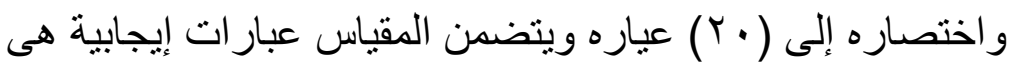

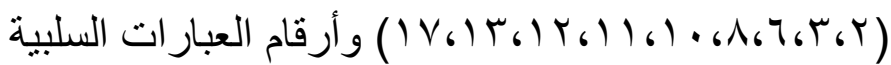
هى(E)

المعاملات العلمية لمقياس السلوك التنافسي في الدراسة الحالية :

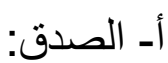

لحساب صدق المقياس استخدت الباحثة صدق الاتساق الداخلي:

للتحقق من صدق المقياس قامت الباحثة بحساب صدق الاتساق الداخلي وذللك بتطبيقه على عينة قو امها (0 1 ) لاعب من لاعبي الاسكواش من مجتمع البحث ومن خارج العينة الأساسية للبحث، ثم قامت الباحثة بحساب معاملات الارتباط بين درجة كل عبارة وبين المجموع الكلي للمقياس، و الجدول (ع) يوضح ذلك

$$
\text { جدول (飞) }
$$

معاملات الارتباط بين درجة كل عبارة من عبار ات مقياس السلوك التنافسى والمجموع الكلى

$$
10=0
$$

\begin{tabular}{|c|c|c|c|}
\hline معاملات الارتباط & رقم العبارة & معاملات الارتباط & رقم العبارة \\
\hline $.594^{*}$ & 11 & $.651^{* *}$ & 1 \\
\hline $.658^{* * *}$ & 14 & $.643^{* *}$ & $r$ \\
\hline $.732^{* * *}$ & r & $.658^{* *}$ & r \\
\hline $.753^{* * *}$ & $1 \varepsilon$ & $.662^{* *}$ & $\varepsilon$ \\
\hline $.651^{* *}$ & 10 & $.712^{* *}$ & 0 \\
\hline $.764^{* * *}$ & 17 & $.723^{* *}$ & 7 \\
\hline $.615^{*}$ & iv & $.721^{* *}$ & V \\
\hline $.830^{* * *}$ & 11 & $.675^{* *}$ & $\Lambda$ \\
\hline $.758^{* * *}$ & 19 & $.680^{* *}$ & 9 \\
\hline $.524^{*}$ & $r$. & $.656^{* *}$ & 1. \\
\hline
\end{tabular}

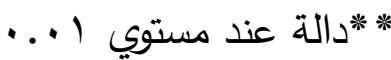

دالة عند مستوي 0 . ..

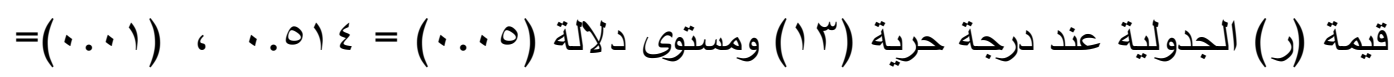


يتضح من جدول (ع) ان معاملات الارتباط بين درجة كل عبارة من عبارات المقياس والمجموع الكلي للمقياس تراوحت ما بين (524.: 830.) وهى معاملات ارتباط دالة احصائياً مما يدل على أن المقياس صادق.

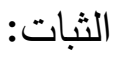
لحساب ثبات المقياس استخدمت الباحثة معامل الفا كرونباخ: للتأكد من ثبات المقياس قامت الباحثة باستخدام معامل ألفا لكرونباخ وذلك بتطبيقه على عينة قوامها (0 1) لاعب من لاعبي الاسكواش من مجتمع البحث ومن خارج العينة الأساسية للبحث والجدول (0) يوضح ذلك.

جدول (0) معامل الفا ( كرونباخ ) لبيان معامل الثبات لمقياس السلوك التنافسى ن= 15

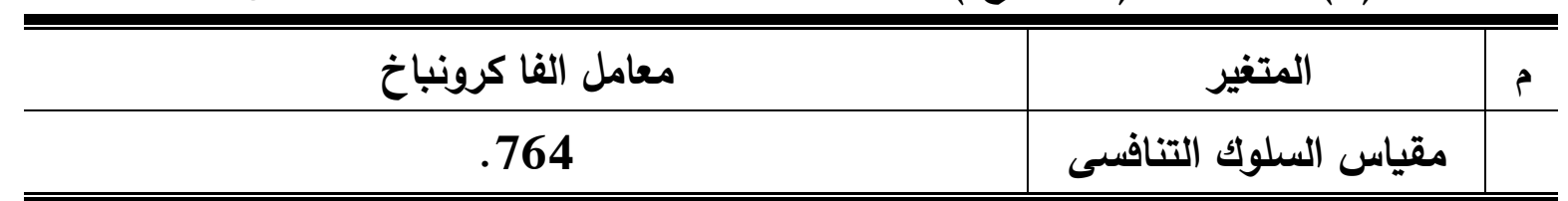

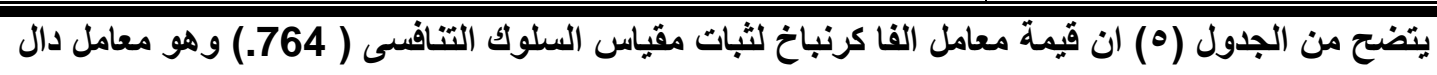

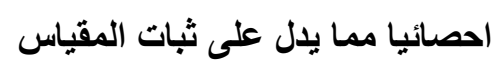

ثنالثا: مقياس دافعية الانجاز في الدراسة الحالية: ملحق (r) وصف المقياس:

قام جون ولس بنقتين مقياس دافعية الانجاز الرياضي وقام محمد علاوي (991 (م) بتعرييه

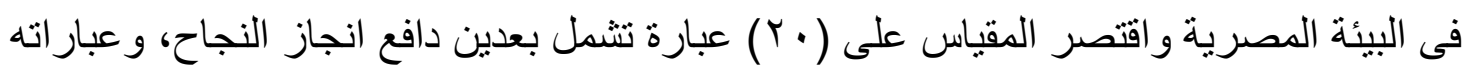

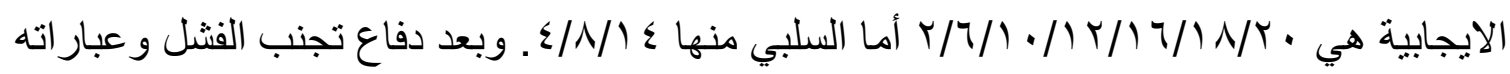

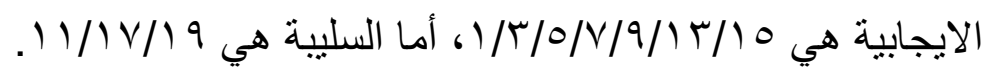

المعاملات العلمية لمقياس دافعية الانجاز في الدراسة الحالية: قامت الباحثة بحساب المعاملات

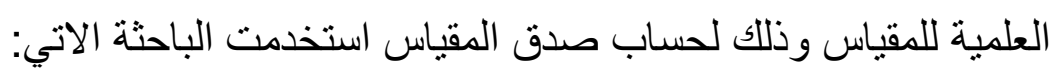

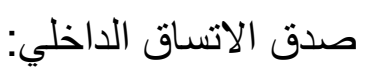

للتحقق من صدق المقياس قامت الباحثة بحساب صدق الاتساق الداخلي وذللك بتطبيقه على عينة قوامها (10) لاعب من لاعبي الاسكواش من مجتمع البحث ومن خارج العينة الأساسية 
للبحث، وقامت الباحثة بحساب معاملات الارتباط بين درجة كل عبارة وبين مجموع درجات البعد الذى تتتمي إلية، وتم حساب معاملات الارتباط بين درجة كل عبارة وبين المجموع الكلي للمقياس، كما تم حساب معاملات الارتباط بين مجموع درجات كل بعد وبين المجموع الكلي للمقياس، و الجداول (T)، (^)، (^) توضح ذلك.

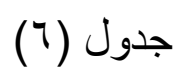

معاملات الارتباط بين درجة كل عبارة من عبار ات مقياس دافعية الانجاز و المجموع الكلي للبعد

$$
\text { الذي تنتمي إليه (ن = }
$$

\begin{tabular}{|c|c|c|c|}
\hline \multicolumn{2}{|c|}{ البعد الثاني دافع تجنب الفشل } & \multicolumn{2}{|c|}{ البعد الأول دافع انجاز النجاح } \\
\hline معاملات الارتباط & رقم العبارة & معاملات الارتباط & رقم العبارة \\
\hline $.648^{* *}$ & r & $.645^{* *}$ & 1 \\
\hline $.643^{* *}$ & 7 & $.648^{* *}$ & $r$ \\
\hline $.647^{* *}$ & 1. & $.651^{* *}$ & 0 \\
\hline $.653^{* *}$ & it & $.657^{* *}$ & $\mathrm{~V}$ \\
\hline $.655^{* *}$ & 17 & $.652^{* *}$ & 9 \\
\hline $.657^{* *}$ & 11 & $.662^{* *}$ & Ir \\
\hline $.645^{* *}$ & $r$. & $.668^{* *}$ & 10 \\
\hline $.645^{* *}$ & $\varepsilon$ & $.649^{* *}$ & 11 \\
\hline $.589^{*}$ & $\Lambda$ & $.658^{* *}$ & iv \\
\hline $.636^{\prime \prime}$ & $1 \leq$ & $.654^{* *}$ & 19 \\
\hline
\end{tabular}

*دالة عند مستوي ه ... **دالة عند مستوي ا ...

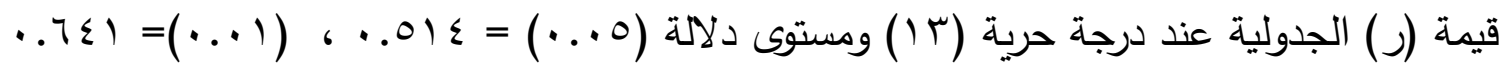
يتضح من جدول (T) ان معاملات الارتباط بين درجة كل عبارة من عبارات المقياس والمجموع الكلي للبعد الذي تنتمي إليه تراوحت ما بين (589.: 668.) وهى معاملات ارتباط دالة احصائياً مما يدل على أن المقياس صادق.

جدول (V) 
معاملات الارتباط بين درجة كل عبارة من عبارات مقياس دافعية الإنجاز والمجموع الكلى للمقياس

$$
10=\dot{0}
$$

\begin{tabular}{|c|c|c|c|}
\hline \multicolumn{2}{|c|}{ البعد الثانى دافع تجنب الفشل } & \multicolumn{2}{|c|}{ البعد الأول دافع انجاز النجاح ـ } \\
\hline معاملات الارتباط & رقم العبارة & معاملات الارتباط & 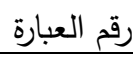 \\
\hline $.668^{* *}$ & $r$ & $.664^{* *}$ & 1 \\
\hline $.665^{* *}$ & 1 & $.663^{* *}$ & $r$ \\
\hline $.663^{* *}$ & 1. & $.665^{* *}$ & 0 \\
\hline $.662^{* *}$ & ir & $.665^{* *}$ & $\mathrm{v}$ \\
\hline $.664^{* *}$ & 17 & $.666^{* *}$ & 9 \\
\hline $.663^{* *}$ & 11 & $.664^{* *}$ & ir \\
\hline $.667^{* *}$ & $r$. & $.667^{* *}$ & 10 \\
\hline $.666^{* *}$ & $\varepsilon$ & $.665^{* *}$ & 11 \\
\hline $.668^{* *}$ & $\Lambda$ & $.662^{* *}$ & iv \\
\hline $.663^{* *}$ & $1 \varepsilon$ & $.665^{* *}$ & 19 \\
\hline
\end{tabular}

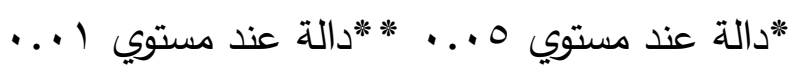

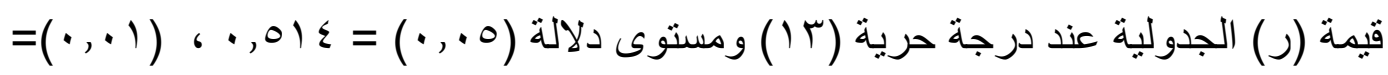

يتضح من جدول (V) ان معاملات الارتباط بين درجة كل عبارة من عبار ات المقياس

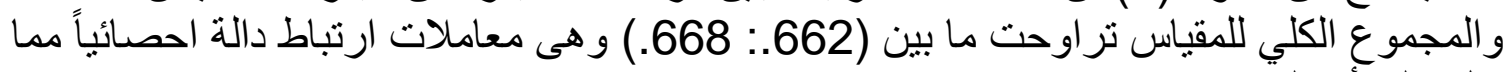
يدل على أن المقياس صني المق

جدول (^)

معاملات الارتباط بين المجموع الكلي لكل بعد من أبعاد مقياس دافعية الانجاز و المجموع الكلي لله

( $10=0)$

\begin{tabular}{|c|c|}
\hline معاملات الارتباط & الابعاد \\
\hline $.762^{* * *}$ & دافع انجاز النجاح \\
\hline $.732^{* *}$ & دافع تجنب الفشل \\
\hline
\end{tabular}

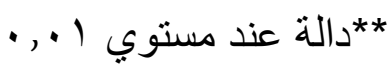

*دالة عند مستوي 0 . , -

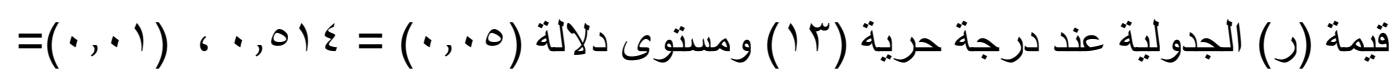

يتضح من جدول (^) ان معاملات الارتباط بين المجموع الكلي لكل بعد من أبعاد مقياس دافعية 
الانجاز و المجموع الكلي له تراوحت ما بين (732.: 762.) و هى معاملات ارتباط دالة احصائياً

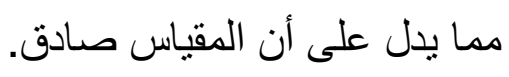

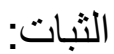

لحساب ثبات المقياس استخدمت الباحثة معامل الفا كرونباخ: للتأكد من ثبات المقياس قامت الباحثة باستخدام معامل ألفا لكرونباخ وذلك بتطبيقه على عينة قو امها (0 1) لاعب من لاعبي الاسكو اش من مجتمع البحث ومن خارج العينة الأساسية للبحث و الجدول (9) (9. (1ضح ذلك.

جدول (9) معامل القا ( كرونباخ ) لبيان معامل الثبات لمقياس دافعية الانجاز ن= 15

\begin{tabular}{|c|c|c|}
\hline معامل الفا كرونباخ & الابعاد & م \\
\hline .794 & دافع انجاز النجاح & \\
\hline .782 & دافع تجنب الفشل & \\
\hline .845 & الدرجة الكلية & \\
\hline
\end{tabular}

يتضح من الجدول (9) ان قيمة معامل الفا كرنباخ لثبات مقياس دافعية الإنجاز تراوحت ما بين

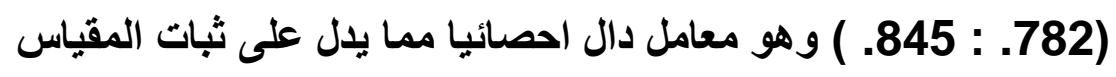

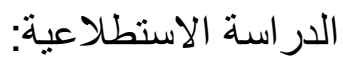

قامت الباحثة بإجر اء الدراسة الاستطلاعية للتأكد من مناسبة المقاييس المستخدمة للتطبيق، وتم تطبيق المقاييس علي عينة قو امها (0 1 ) لاعب من لاعبي الاسكو اش من مجتمع البحث ومن خارج

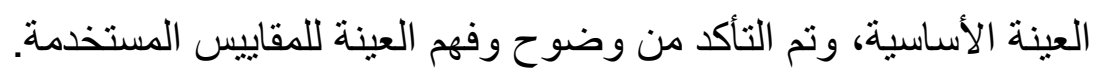

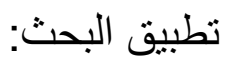

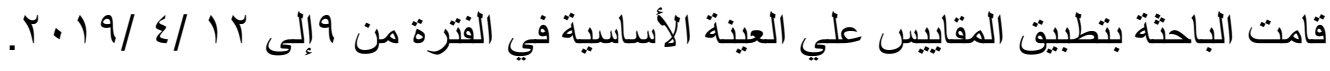
الأسلوب الإحصائي المستخدم: - المان

لحساب نتائج البحث استخدمت الباحثة الأساليب الاحصائية الآتية:

$$
\text { المتوسط الحسابي. الوسيط. }
$$

الانحر اف المعياري. معامل التفلطح - معامل الالنواء. 


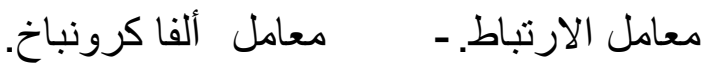

وقد ارتضيث الباحثة بمستوى دلالة عند مستوى (0 + , •، 1 . , • ) للتأكد من دلالة النتائج

الاحصائية للبحث، كما استخدمت الباحثة ة برنامج Spss لحساب المعاملات الاحصائية.

\section{عرض النتائج وتفسيرها ومناقشته}

جدول ( • () علاقة الارتباط بين التوجه التنافسى و متغيرات دافعية الإنجاز (دافع انجاز النجاح ـ دافع تجنب الفشل - الدافعية الكلية ) و السلوك التنافسى ن = • ب

\begin{tabular}{|c|c|}
\hline التوجه التنافسي & المتغير ات \\
\hline 262 & دافع انجاز النجاح \\
\hline .134 & دافع تجنب الفشل \\
\hline $.391^{*}$ & الدافعية الكلية \\
\hline-.204 & السلوك التنافسى \\
\hline
\end{tabular}

يتضح من الجدول ( · () الخاص بعلاقة الارتباط بين التوجه التنافسى و متغيرات دافعية

الإنجاز ( دافع انجاز النجاح ـ دافع تجنب الفشل ـ الدافعية الكلية ) و السلوك التنافسى انه توجد علاقة ارتباط طردية إجابيه دالة إحصائية بين التوجه التنافسى و الدافعية الكلية للإنجاز حيث بلغت ( 391. ) , وكذلك يوضح عدم وجود ارتباط دال احصائيا بين بقية المتغيرات وهى ( دافع انجاز النجاح - دافع تجنب الفشل - السلوك التنافسى)

وترجع الباحثة هذه النتيجة الى ان الاعبين في هذه المرحلة السنية يتميزون باضطر ابات في عملية التوجه لتحقيق الأهداف.

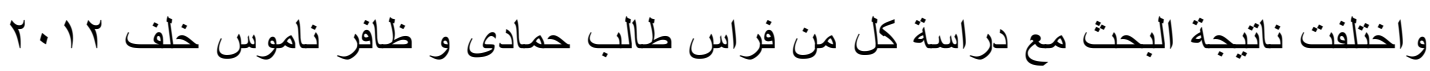

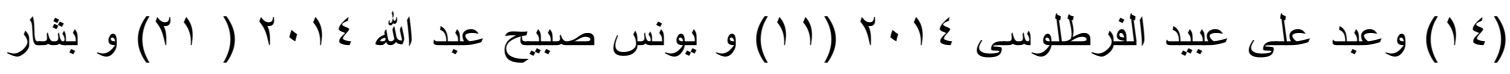

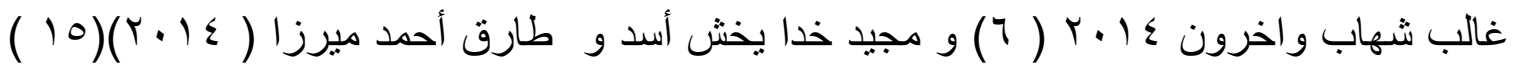

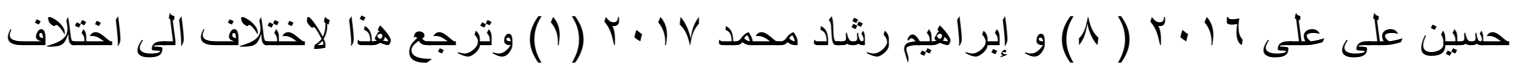
المر احل السنية عن المرحلة السنية المستخدمة في البحث .

و هذا ما اكدة على محمد مطاوع ان الرغبة بـالفوز في المنافسات تـزداد مـع زيـادة العمـر و المكافـأة

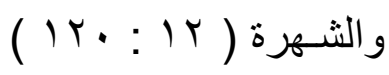




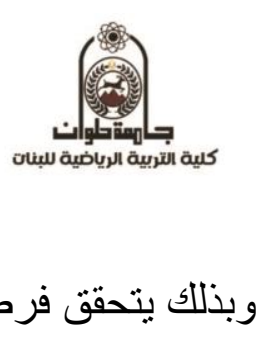

- توجد علاقة ارتباط ذات دالة معنوية بين التوجه التنافسى والدافعية الكلية لدى ناثئ الاسكو اش.

- توجد علاقة ارتباط غير دالة معنوية بين التوجه التنافسى والسلوك التنافسى لاى ناثئ الاسكو اش.

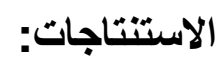

فى حدود مشكلة البحث وأهميته وفى ضوء هدفه وفروضه وطبيعة العينة وفى إطار المعالجات الإحصائية وتفسير ومناقثة النتائج توصلت الباحثة إلى الاستنتاجات الآتية: علاقة الارتباط بين التوجه التنافسى ومتغيرات دافعية الإنجاز (دافع انجاز النجاح ـ دافع تجنب الإنب النجاء الفشل - الدافعية الكلية) و السلوك التنافسى - توجد علاقة ارتباط موجبة غير دالة معنوية بين التوجه التنافسى ودافع انجاز النجاح لدى ناثنئ الاسكو اش. - توجد علاقة ارتباط موجبة غير دالة معنوية بين التوجه التنافسى ودافع تجنب الفنش لدى ناثنئ الاسكو اش. - توجد علاقة ارتباط موجبة ذات دالة معنوية بين التوجه التنافسى والدافعية الكلية لدى ناشئ الاسكو اش. - توجد علاقة ارتباط سالبة غير دالة معنوية بين التوجه التنافسى والسلوك التنافسى لدى ناشئ الاسكو اش. ا - ضرورة الاهتمام بتنمية الصفات النفسية قيد البحث لناشئ الاسكو اش للاستفادة منها في تحقيق الفوز احراز البطو لات التي يشاركون بها.

ץ- ضرورة عمل دور ات تدريية للمدربين لتنمية الصفات و القدر ات العقلية وخاصة في فترة ما قبل المنافسة بصفة عامه من قبل الاتحاد. r- عقد دورات تثقيفية للاعبين لبيان اهمية تنمية الصفات و القدرات العقلية من قبل الاتحاد. 


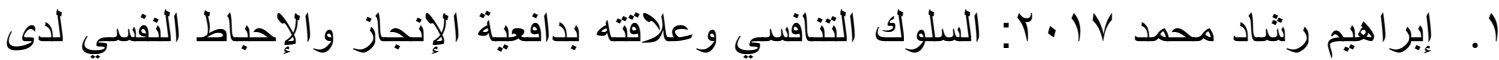
لاعبي المنتخبات الرياضية بجامعة المنيا ، مجلة أسيوط لعلوم وفنون التربية الرياضية ،

$$
\text { r. }
$$

r. احمد امين فوزى، طارق محمد بدر الدين I ... ب: سيكولوجية الفريق الرياضى ، طا ، دار

الفكر العربى ، القاهرة

ץ. أحمد ماهر 99 1 : السلوك التنظيمي مدخل بناء المهار ات، الاسكندرية، دار الجامعية، صبr

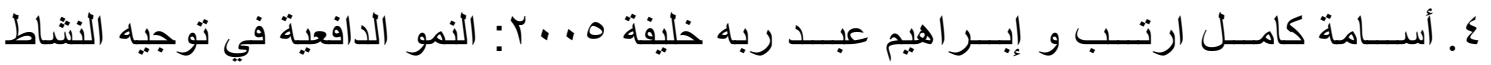

الحركى للطفل والأنثطة الرياضية المدرسية، دار الفكر العربى , القاهرة ๑. أسيل مجيد ثلج 1 ـ ب : علاقة الاستثارة الانفعالية بمستوى أداء بعض المهارات الأساسية في الأسكو اش لطلاب المرحلة الثالثة في كلية التربية البدنية جامعة بغداد ـو علوم الرياضة،

مجلة كلية التربية الرياضية- جامعة بغداد** المجلد الثامن و العشرون ** العدد الرابع

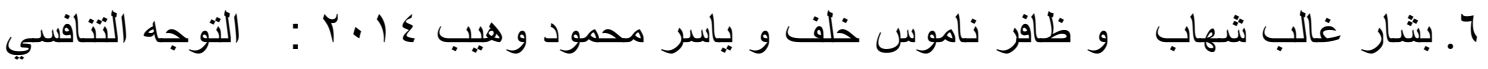
و علاقته بدافعية الإنجاز الرياضي و السلوك التنافسي لدى لاعبي المبارزة ، جامعة ديالى ، كلية

$$
\text { التربية الرياضية }
$$

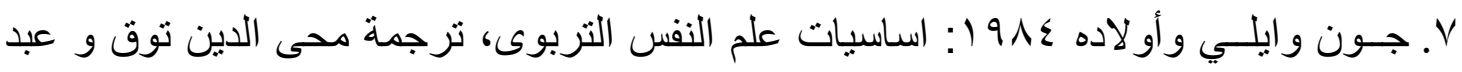

$$
\text { الرحمن عدس , مطبعة جون ويلى , عمان }
$$

^. حسين على على 17 • Y: دافعية الإنجاز وعلاقته بالسلوك التنافسي وأداء بعض المهارات

$$
\text { الأساسية بكرة القدم، جامعة صلاح الدين، كلية التربية الرياضية }
$$

9. صدقي نور الدين محمدء . . ب: علم النفس الرياضي (المفاهيم النظريةــ التوجيه والإرشادـ

$$
\text { القياس)، الإسكندرية، المكتب الجامعي الحديث، }
$$

• . . عبد الرحمن عدس و نايف قطامى . ... . مبادئ علم النفس، طا ، دار الفكر للطباعة

$$
\text { النشر ، الن عمان }
$$

1ا. عبد على عبيد الفرطلوسى ؟1 . ب: السلوك التنافسي وعلاقته بدافعة الارجاز لدى لاعبي

ألعاب القوى بالجامعة المستنصرية ، مجلة القادية لعلوم التربية الرياضية المجلد ع ا العدد r

$$
\text { الجزء }
$$

r ا. . على محمد مطاوع 9VV 19V سيكولوجية المنافسات ، دار المعارف ، القاهرة 
rا . علي عطية دخيل، نعمان هادي Y V. P : تأثثر التغذية الراجعة المستمرة في تعلم مهارة الرسال العالي للاعبي الاسكواش الناشئين ، المجلة الدولية للبحوث الرياضية المتقدمة،

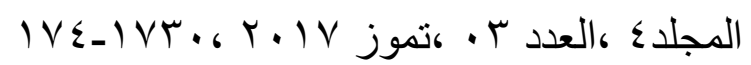

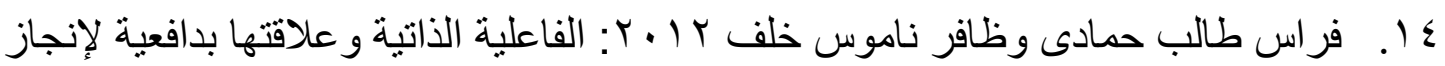
و السلوك التنافسي لدى لاعبي المبارزة ، مجلة كلية التربية الأساسية العدد V ، جامعة بابل ، كلية التربية الرياضية 1 . . مجيد خدا يخث أسد و طارق أحمد ميرزا ع ا. ب : التوجه التنافسي وعلاقته بالسلوك التنافسي و الإنجاز لاى لاعبى اندية كوردستان بالعاب القوى ، مجلة جامعة بابل / العلوم الإنسانية / المجلد ب / / العدد ع

1 ا. محمد حسن علاوى 1991: سيكولوجية الجماعات الرياضية، مركز الكتاب للنشر ، القاهرة

V I . محمد حسن علاوي ؟ . . ب: مدخل في علم النفس الرياضي، طا، القاهرة، مركز الكتاب للنشر

1 ا. . محمد حسن علاوي/99 19 : مدخل في علم النفس الرياضي، القاهرة، مركز الكتاب للنشر 9 19. محمود عبد الفتاح عنان 990 1: سيكولوجية التربية البدنية النظرية والتطبيق والتجريب ، دار الفكر العربى ، القاهرة •r. . يحى قذيفة ع ا • r: تقدير الذات البدنية وعلاقتها بالتوجه الرياضي لتلاميذ أقسام التربية البدنية والرياضية لمتوسطات ولاية المسيلة، رسالة ماجستير، معهد علوم وتقنيات النشاطات

$$
\text { البدنية و الرياضي، جامعة الحاج لخضر -باتنة-، الجزائر }
$$

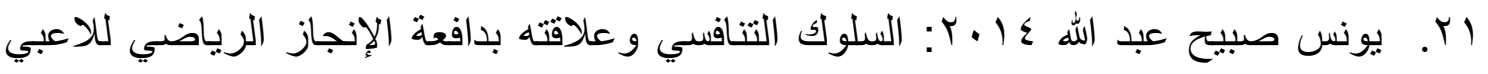
الدوري الممتاز في المنطقتين الوسطى والجنوبية لكرة القدم، رسالة ماجستير، كلية التربية

$$
\text { الرياضية، جامعة البصرة }
$$

22. Gill,D. L \& Deeter , T.E 1988: Development of Sport Orintation questionnaire Quartenly for Exercise and Sport Vol-5 23. Jeffrey C. Ives, Kristin Neese, Nick Downs, Harrison Root, Tim Finnerty 2020: The Effects of Competitive Orientation on Performance in Competition, thesportjournal.org, ISSN: 1543-9518|Vol. 21 